\title{
Membrane Biology
}

National Cancer Institute

\section{Source}

National Cancer Institute. Membrane Biology. NCI Thesaurus. Code C19430.

The study of the protoplasmic boundary of all cells that controls permeability and may serve other functions through surface specializations; e.g., active ion transport absorption by formation of pinocytotic vesicles; receptor-mediated antigen recognition, etc. 